\title{
Pathophysiological and clinical aspects of the diagnosis and treatment of bezoars
}

\author{
Konstantinos A. Paschos, Anestis Chatzigeorgiadis
}

General Hospital of Drama, Greece

\section{Abstract}

\section{Introduction}

Bezoars constitute concretions of poorly or non-digested material that develop within the gastrointestinal (GI) tract. The word bezoar originates from the Arabic term "badzehr" or potentially the Persian word "padzahr"; both mean to expel a poison, counterpoison or antidote. The aforementioned words were applied to describe a greenish, hard concretion in the animal stomach, formerly considered a useful medication, sometimes with certain magical properties [1]. In 1854, an Irish anatomist and surgeon of the University of London (UCL), Richard Quain, reported a mass in the stomach, found on autopsy, which he called "bezoar" [2].

A variety of materials received orally intentionally or accidentally may form these indigestible masses. Consequently, several types of bezoars have been described, including

Department of General Surgery, General Hospital of Drama, Greece

Correspondence to: Konstantinos A Paschos MD, MSc, PhD, Consultant Surgeon, Department of General Surgery, General Hospital of Drama, Greece, Terma Ippokratous St, 66100 Drama, Greece, e-mail: kostaspaschos@yahoo.gr

Conflict of Interest: None

Received 11 December 2018; accepted 11 February 2019; published online 15 March 2019

DOI: https://doi.org/10.20524/aog.2019.0370 phytobezoars (fibers, fruit remnants, skins of vegetables, etc.), trichobezoars (ingested hair), pharmacobezoars (medications), lactobezoars (milk protein in milk-fed babies and infants), and others. Interestingly, bezoars may be formed in any segment of the GI tract. However, the stomach is the most common organ of bezoar formation. Their diagnosis is made either endoscopically or radiologically, while the therapeutic approach follows, as they may cause serious symptoms $[3,4]$. This study aims to investigate current data concerning the epidemiology, diagnosis and therapy of bezoars, attempting to offer a better understanding of this rare entity that may appear with multiple types and complications.

\section{Classification of bezoars}

\section{Phytobezoars}

These constitute the most common type of bezoars. The first root of this compound term is derived from a Greek word $\varphi v \tau o$ (phyto), which means plant. Phytobezoars are composed of vegetable and/or fruit matter, such as celery, prune, apricots, grape skin, orange, raisin, watermelon, pumpkin, mushroom or persimmon. The main components of these indigestible food materials may be cellulose or hemicellulose, tannin and/ or lignin $[5,6]$.

Cases with persimmon phytobezoars are the most frequent and challenging ones, attributed to increased consumption of 
the fruits of the plant genus Diospyros (Greek word dios=Zeus and $p y r=$ fire, meaning divine food). Certain species of this plant are also named "lotus" tree, first mentioned and becoming widely known through Homer's epic poem, the Odyssey. It has been stated that persimmons contain high concentrations of tannin, which, when in contact with gastric acids, polymerize to form conglomerates consisting of cellulose, hemicelluloses and other proteins. In that way persimmon tannin acts as an adhesive agent that holds and sticks plant fibers together, thus supporting the formation of indigestible materials and masses [7]. Interestingly, Maki et al described the experimental formation of a solid hard mass, mimicking phytobezoars, using pieces of persimmon skin, hydrochloric acid (which present in the stomach), and organic and inorganic polymers as coagulating agents. These in vitro experiments were based on previous research on the coagulation and solidification of bile, and included multiple steps in order to specify the optimal conditions of coagulation and the associated natural and commercially available products. Although original and interesting, this methodology and its results were not reproduced by other groups [8]. A recent experimental study by Iwamaro et al investigated the elemental composition of persimmon bezoars, showing that higher amounts of iron and sulfur are accumulated in the surface rather than the core of the masses, the iron explaining the dark color of the exterior of persimmon phytobezoars, while yttrium and aluminum were also detected. This study included many technologically advanced methods, such as scanning electron microscopy, infrared spectroscopy analysis and energy-dispersive $\mathrm{x}$-ray spectroscopy. Although the phytobezoar specimen was recovered from a single patient and osmium may have contaminated the samples during the fixing process, these results may explain phytobezoar formation to a certain extent. However, the data need to be reproduced in multiple specimens by different research groups [9].

\section{Pharmacobezoars}

The first root of this term is derived from the Greek word фа́рнкко (pharmako), which means medication. These are uncommon masses caused by conglomerates of medications, including kayexalate, antacids or cholestyramine. Medication vehicles and specific drug action may be the reason for pharmacobezoar formation. Slowly dissolved and gradually released drugs, such as verapamil, cefaclor, felodopine, nifedipine, etc., are coated with cellulose acetate, which allows prolonged and delayed administration of the chemical compounds. However, cellulose may aggregate, thereby causing the formation of bezoars in the digestive tract. In addition, enteric-coated medications, such as aspirin, sulfasalazine, omeprazole, etc., use an insoluble carrier to protect the active medical compound from the low gastric $\mathrm{pH}$ (high acidity), permitting its dissolution in a higher $\mathrm{pH}$ in the intestine. Unfortunately, because of its insolubility, this polymer carrier may contribute to bezoar formation. Likewise, bulk-forming agents that treat constipation, such as psyllium, polycarbophil, methylcellulose, etc., may also trigger the formation of pharmacobezoars through their hygroscopic properties [10-12]. Recently, a methadone double pharmacobezoar was reported, causing coma in a drug-addicted male psychiatric patient. It was revealed endoscopically and treated through repetitive gastric lavages for 5 days. The patient survived after staying intubated for 7 days in the Intensive Care Unit. Methadone tablets that formed this pharmacobezoar may have adhered because of the patient's dehydration, in association with a gastroparetic effect of multiple antipsychotic drug use (anti-cholinergic action) [13].

\section{Trichobezoars}

Bezoars are named as trichobezoars from the Greek word $\tau \rho i \chi \alpha$ (tricha=hair) when they contain hairs. These are rare masses that are almost always discovered in the stomachs of young women. Notably, certain psychiatric disturbances are associated with the development of trichobezoars, such as trichotillomania, defined as a compulsory hair pulling disorder, and trichophagia (Greek parciv; phagein=to eat) defined as compulsive eating of one's hair $[14,15]$. However, only one third of the patients diagnosed with trichobezoars suffer from trichophagia and only $1 \%$ present symptoms that may require surgical treatment $[16,17]$. The first case was described and reported by Baudomant in 1779, whereas the first surgical removal of such a mass was performed by Schonbern in 1883 [18]. Hair holds enzyme-resistant properties due to its smooth and slippery external surface; consequently, instead of being digested in the digestive tract, hairs accumulate among the folds of the gastric mucosa and may finally form a mass when they stick together with mucus and food remnants. This mass may be palpable, as their weight may reach several kilograms and up to $6.2 \mathrm{~kg}[19,20]$. Most interestingly, trichobezoars may rarely extend from the stomach, where they form their main body, to the small intestine or the ascending colon, thereby presenting a long tail; this pathological entity is termed Rapunzel syndrome [18]. Around 120 cases of this syndrome have been described in the medical literature. Naik et al reviewed 24 cases in 2007 [21], while Ullah et al reported 88 cases until 2016 [22]. Fallon et al described the longest case series of 7 patients in 2013. All were young female persons, 5-23 years of age, with psychiatric disorders. Notably, $85 \%$ of these patients were accurately diagnosed prior to laparotomy, based only on their medical history and radiography rather than endoscopy [23].

\section{Lactobezoars}

These are undigested masses from concentrated infant milk formula and mucus. All recorded cases refer to milk-fed infants and the masses are usually located in the stomach, but may also appear in other parts of the digestive tract. The first description of this rare entity was in 1959 and about 110 more cases have been reported since then [24]. Interestingly, prematurity and low birth weight appear to be the main pathogenic factors, although the disease has been diagnosed in full-term infants and toddlers. Additional factors contributing to the pathogenesis are 
the milk-formula composition, dehydration, antacid medical treatment, as well as the methodology of feeding. Accumulating data suggest that the high caloric and protein concentration of synthetic milks may exceed the digestive capacity of premature neonates, because of the decreased enzyme activity in their GI tract and salivary glands, thus leading to the formation of lactobezoars [25]. Notably, in the last 31 years (1987-2018) 40 cases of lactobezoars have been reported in the English literature, while according to Heinz-Erian et al, in the previous 30 years (1959-1986) 70 cases were described [26]. The decreased incidence of lactobezoars in recent years may be attributed to the improvement in synthetic milk composition, improvements in premature neonate medical care, or the increased rates of breastfeeding in the last decades. Most interestingly, these masses do not appear in infants receiving only human milk.

\section{Other types of bezoars}

Apart from the aforementioned types of bezoars, other substances may also contribute to their formation: unusual and peculiar materials that have been described in the past include metals [27,28], ceramics (kaolin) [29], fungi (Candida) [30], plastic, parasites (ascaris) and paper [4]. In the future, more materials may be recorded as bezoar contributors, because all indigestible food substances and foreign bodies may cause the formation of a mass in the digestive tract with the sticky intervention of mucus.

\section{Prevalence}

Multiple studies have attempted to assess the incidence of bezoars, although with variable results. However, it is widely accepted that it is an infrequent pathological entity. In 1978, Kadian et al described 6 cases of gastric bezoars out of 1400 upper GI endoscopies during 4 years, yielding an incidence of $0.43 \%$ [31]. Similarly, in 1987, Ahn et al described 14 cases out of 3247 upper GI endoscopies during 7 years, with the same incidence (0.43\%) [32]. In 2013, Mihai et al presented 49 bezoar cases from a 20 -year period, 34 of which were phytobezoars, arriving at a lower incidence of $0.068 \%$ [33].

Although bezoars are predominantly formed and discovered in the stomach, they may migrate to the small or the large intestine; even more rarely, they may develop in the small intestine. When trapped in the small intestine, bezoars may cause ileus. Dervisoglou et al studied 369 patients with acute intestinal obstruction over 5 years and concluded that $2.39 \%$ were attributed to bezoars, constituting the fifth most frequent cause [34]. Likewise, Kirshtein et al analyzed 65 patients who underwent laparoscopic treatment for small bowel obstruction over 6 years and revealed 3 cases caused by bezoars, representing the fifth most common cause (4.6\%) [35]. Yakan et al reviewed 432 patients who received surgical treatment for small bowel obstruction over 10 years and reported that phytobezoars were responsible in 14 cases (3.2\%) [36].
Subsequently, accumulating data from clinical studies suggest that gastric bezoars are discovered in less than $0.5 \%$ of all upper GI endoscopies, while bezoars present in the small intestine may be the cause of ileus in $0.4-4.8 \%$ of all cases of intestinal obstruction. Interestingly, the prevalence of phytobezoars, which constitute the most common form, varies among countries and ethnic groups, because of the cultivation of certain plants, the diet, as well as ethnic or religious nutritional habits [37]. Persimmon phytobezoars, for example, are mainly reported in countries that produce and export the plant (China, South Korea, Japan, Brazil) or present high consumption due to local tradition (Turkey, Spain, etc.). Concurrently, more rare bezoars, such as tricho- paper- and metal-bezoars, are associated with certain psychiatric disturbances, more common in developed countries and poor or uneducated populations $[4,38,39]$.

\section{Predisposing factors}

Numerous factors may contribute to the formation of bezoars. Previous gastric surgery appears to be the most common risk factor: $20-93 \%$ of the patients diagnosed with bezoars have a relevant history, while the incidence of bezoar formation in patients who undergo gastric surgery is $5-12 \%$. Specifically, vagotomy and partial gastrectomy performed for chronic ulcers substantially reduce the acidity and quantity of gastric juices, thus adversely affecting peptic activity. Concomitantly, pyloroplasty, antrectomy or gastrojejunostomy result in a wide gastric outlet. Taking into consideration that the gastric antrum regulates the mechanical fragmentation of food particles and the pylorus acts as a doorkeeper that deters the passage of large boluses, such operations facilitate the passage of maldigested large food boluses to the duodenum and the small intestine, predisposing to bezoar formation. Interestingly, these masses may be formed within 9 months to 30 years after gastric surgery, according to various studies $[2,7,40]$.

More rarely, bezoars may appear primarily in the small intestine, causing intermittent or permanent intestinal obstruction. In these cases, intestinal motility is significantly disturbed by pathological entities, such as diverticuli, strictures or neoplasms [41,42].

Excessive consumption of high-fiber foods may also contribute to the formation of phytobezoars. Unripe fruits or vegetables, regularly consumed in great quantities and rapidly swallowed in association with poor mastication appear to be reliable predisposing factors. In particular, immature persimmons contain tannins, which play a critical role in phytobezoar formation [43].

Less common predisposing factors have also been mentioned in the literature. These include medications that delay gastric motility, rapid swallowing of large amounts of foods, poor mastication due to artificial dentures (mainly in the elderly) and diseases such as mental retardation (e.g., trichobezoars), hypothyroidism, diabetes mellitus, renal failure or postoperative adhesions [7]. Most interestingly, certain studies have described patients with bezoars in whom no predisposing factor could be identified, suggesting 
the existence of factors that may act intermittently and for a short time, such as eating/dietary habits or temporary acid alterations in the stomach [44].

\section{Manifestations and diagnostic approach}

Bezoars may be asymptomatic or they may present various symptoms and signs from the GI tract. Most commonly, they may cause abdominal discomfort, fullness or pain, difficulty in swallowing, or anorexia. Furthermore, symptoms related to GI bleeding, such as anemia, tarry or bloody stools, hematemesis and fainting, may result from ulcers and mucosa necrosis from bezoar-related intraluminal pressure [45]. In the rare cases of complete intestinal obstruction or perforation, the patient may present with serious manifestations of acute abdomen, vomiting, abdominal distension, hypotension, mental disorientation and shock $[46,47]$.

Modern endoscopes using high definition visualization facilitate the detection of gastric or upper GI bezoars. Typically, they appear as single masses in the gastric fundus, with various colors (black, green, beige or other, according to composition). However, they may be multiple or very rarely be impacted in the esophagus or duodenum $[4,48,49]$.

Radiological imaging also plays a crucial role in the diagnostic approach. Plain X-rays may show air-fluid levels that suggest intestinal obstruction, while barium studies may contribute to the differential diagnosis among intestinal diverticuli, adenomas, malignancies and bezoars (Fig. 1). Unfortunately, these studies are insufficiently accurate and are inappropriate for detailed emergency investigation, or for the preoperative assessment of intestinal perforation or complete obstruction [50]. Undoubtedly, contrast-enhanced computed tomography (CT) scanning is the radiological method of choice, showing high sensitivity (up to 90\%) and specificity (up to 60\%). Phytobezoars, the most common bezoars, are visualized as round or ovoid masses with air-bubbles and a mottled appearance [51] (Fig. 2). Interestingly, they may appear similar to small bowel feces; the latter are discovered in about $8 \%$ of cases with ileus. It should be noted that, on radiological imaging, feces tend to appear in a longer segment and are associated with sharp-margin dilatation compared to bezoars, which tend to slide back and forth intraluminally [52,53].

Additionally, a CT scan enables the detection of multiple bezoars and the exclusion of other causes of intestinal obstruction, shows in detail the condition of intestinal loops (edema, strangulation, ischemia, accumulation of intra-abdominal fluid), and permits accurate preoperative planning [54]. In general, a CT diagnosis of a bezoar is followed by surgery within $48 \mathrm{~h}$.

\section{Therapeutic approach}

The treatment of bezoars depends on their volume, chemical synthesis, location and associated pathology. Currently, there are multiple treatment options available, such as dissolution with

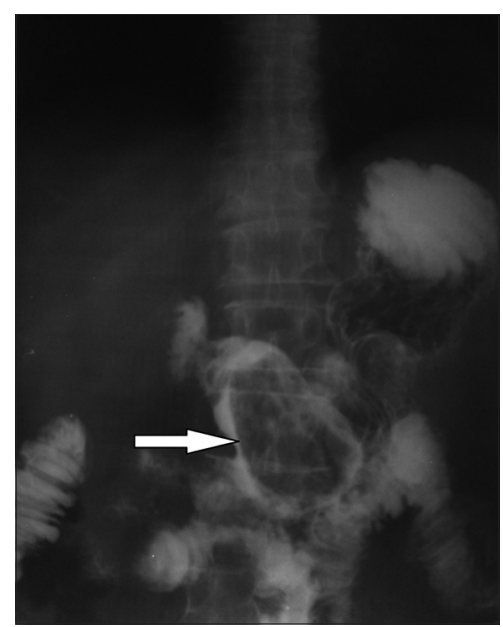

Figure 1 Abdominal radiography with per os administration of an iodinated contrast medium shows a gastric phytobezoar as a filling defect (arrow)

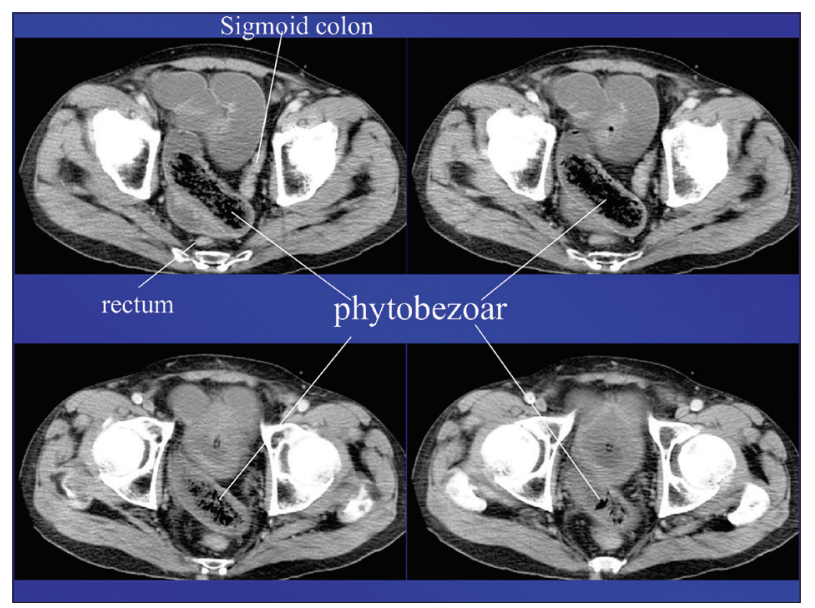

Figure 2 Contrast-enhanced computed tomography showing a phytobezoar in ileal loops causing intestinal obstruction (characteristic mottled appearance)

various compounds, endoscopic fragmentation and removal, laparotomy and laparoscopic surgery. Notably, in the case of an intestinal obstruction or more rarely a gastric obstruction, gastric and intestinal decompression along with fluid and electrolyte replacement should be the initial therapeutic step, aiming to treat imbalances resulting from vomiting and fluid accumulation within the obstructed intestinal loops; bezoar removal should follow [7] (Fig. 3).

\section{Chemical dissolution}

Saline solution, hydrochloric acid, sodium bicarbonate, CocaCola $^{\oplus}$ (CC) and enzymatic agents (e.g., papain, cellulase, pancreatin) have all been described, alone or in association, as potentially effective for bezoar resolution with various rates of success. However, no consensus has been established as to the quantity, the density and the time of action for each of these 
substances. Consequently, each researcher or clinician follows a different methodology [55-58].

CC is the most popular chemical agent used to dissolve phytobezoars successfully. Ladas et al reviewed 46 patients from various studies and found a $91 \%$ resolution rate of phytobezoars with CC, either alone or in conjunction with an endoscopic procedure. They recommend gastric lavage with $3 \mathrm{~L}$ of CC administered per os or through nasogastric tubes [58]. Mihai et al treated each of 12 patients with $4.8 \mathrm{~L}$ of CC for $12 \mathrm{~h}$, achieving $42 \%$ complete resolution and the same percentage of fragmentation [33]. Although these results are promising, there is no consensus on the dose or time of action for CC use. In particular, old patients with a history of gastric ulcer and diabetes mellitus may present serious complications (ulcers, electrolyte disorders, etc.) when treated with excessive amounts of CC. Moreover, pieces from bezoar fragmentation

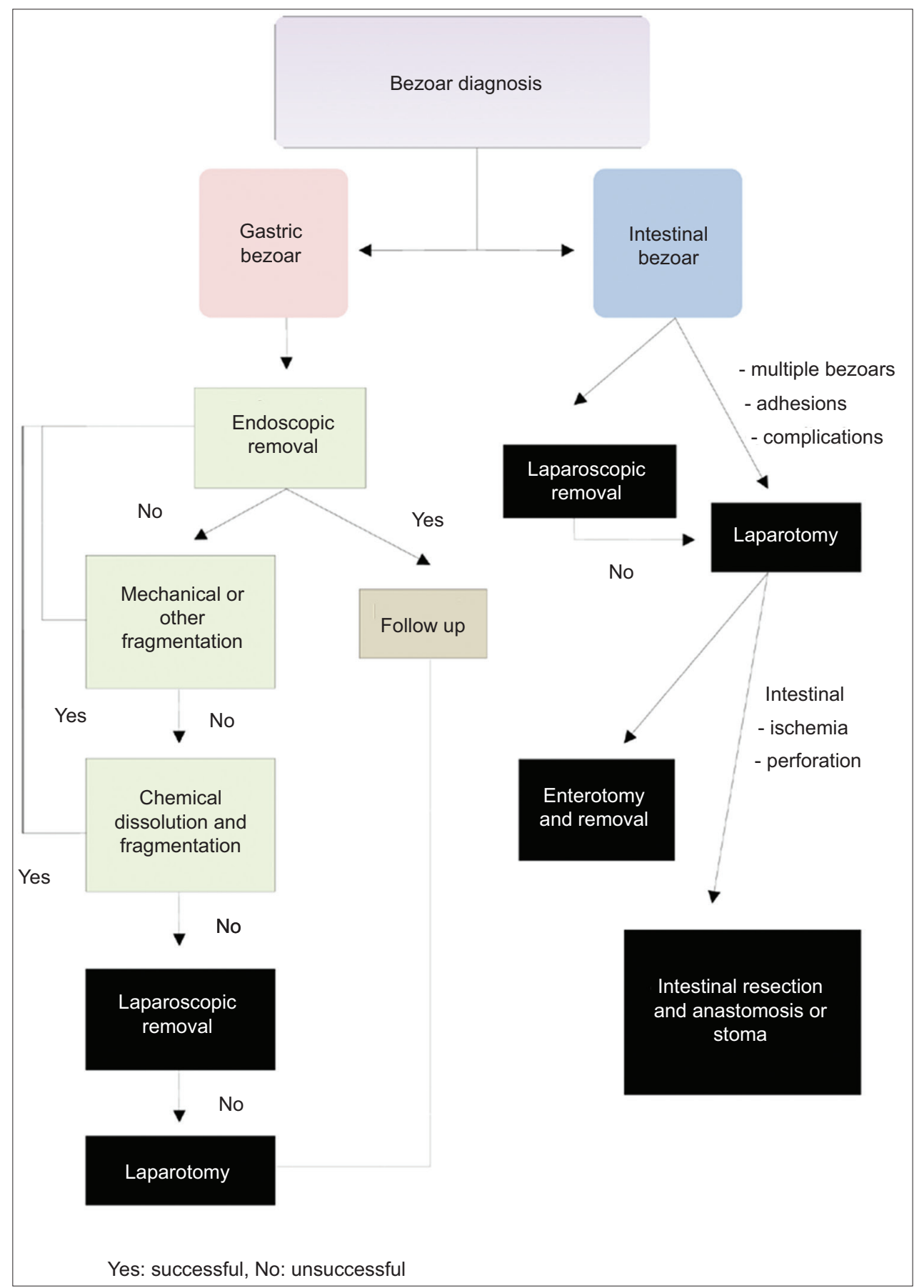

Figure 3 Therapeutic approach following the diagnosis of a gastric or intestinal bezoar. There are multiple options, including chemical dissolution, endoscopic removal, laparoscopic or open surgery 
may obstruct the pyloric outlet and/or migrate to the small bowel causing ileus $[59,60]$. Therefore, more studies are needed to assess and establish this method.

Cellulase has also been used in phytobezoar treatment. The rationale lies in the fact that vegetables and fruits contain considerable amounts of cellulose and cellulase could degrade this polysaccharide by cleaving its glycosidic bonds [61]. In 1968, Pollard and Block initially described the successful resolution of a bezoar with cellulase action [62]. Although this enzyme is usually administered in association with other enzymatic agents, its efficacy has been questioned by other studies; as cellulase is not commercially available in many countries or as a prescribed medication, this compound has rather limited use nowadays [4,9].

In general, chemical dissolution may be used on all types of gastric bezoars. However, persimmon phytobezoars, as well as trichobezoars, are resistant because of their consistency and the results are poor even after prolonged treatment. Furthermore, extensive administration of enzymes, such as cellulase or pancreatin, may cause esophageal and gastric ulcers, electrolyte disturbances, abdominal pain, nausea and vomiting, or more rarely anaphylactic reactions. Notably, a detailed medical history should investigate the question of heart or blood vessel disease, allergies to any medicine, as well as liver or pancreatic disorders.

\section{Endoscopic fragmentation and removal}

Since the most common bezoar location is the stomach, gastroscopic methods have prevailed in the treatment of gastric bezoars. Mechanical disintegration may be achieved using lithotripters, biopsy forceps, polypectomy snares of various size, argon plasma coagulation devices, electrosurgical knives and laser devices. Fragments may be removed using snares and Dormia baskets [63-65]. Trichobezoars are usually resistant and require surgical removal, although fragmentation with an electrosurgical knife has been mentioned [66].

\section{Surgical procedures}

If bezoars are diagnosed in the lower GI, or cause ileus, intestinal ischemia and perforation, as well as when other modalities have been unsuccessful, then surgical intervention and removal is mandatory. Bezoar-induced obstruction is most frequently revealed in the distal end of the small bowel, less than $100 \mathrm{~cm}$ proximal to the ileocecal valve. The etiology could be the decreased diameter of the lumen towards the valve, the lower motility of the small bowel near the valve, or the increased water absorption at the ileal distal end, which may cause dysmotility and adhesion of the bezoars to the intestinal mucosa [3].

The main operation is enterotomy and removal of the mass (Fig. 4). The milking technique, to advance the mass either proximally towards the stomach or distally through the ileocecal valve, has also been performed. However, successful removal is not guaranteed and complications such as laceration of intestinal serosa or mesentery and mucosal bleeding can occur [36]. Experimental studies on rats showed significant postoperative peritoneal adhesions and positive peritoneal cultures in cases where the milking technique had been performed [67]. Obviously, when ischemia and/or perforation occur, the aforementioned techniques are not therapeutic and thus segmental resections with anastomosis and/or stoma are the preferable procedures [7].

Although open surgery for bezoar removal has been wellestablished for decades, laparoscopic abdominal exploration is increasingly being performed nowadays. Notably, laparoscopic surgery is performed only in properly equipped medical centers; it requires technical experience and detailed preoperative evaluation (clinical, radiological, endoscopic). Meticulous preoperative study is necessary, because dilated intestinal loops, adhesion from previous operations, multiple bezoars or even worse complications (including perforation and/or peritonitis) may jeopardize or prevent the laparoscopic approach $[68,69]$. Interestingly, laparoscopy offers bettermagnified visualization of the whole abdomen (although palpation is not possible), as well as fewer complications and a shorter hospital stay when it is properly performed by experienced surgeons [70]. The laparoscopic removal of giant gastric bezoars has been reported in selected patients, although the location of the gastric incision and the risk of abdominal contamination should be seriously considered [71,72].

\section{Other options and strategies}

Laparoscopic and endoscopic cooperative surgery, a combined technique introduced for upper GI tumor resection a decade ago, has also been performed successfully for gastric bezoar extraction. Although only 2 cases have been described until now-a gastric trichobezoar $29 \times 10 \mathrm{~cm}$ in size and another gastric bezoar $10 \mathrm{~cm}$ in diameter-this combined technique may become a favorable therapeutic option in the near future. It offers small incisions and intragastric access through laparoscopic surgery, with the aid of endoscopic visualization that provides accurate intraoperative control and evaluation of the surgical interventions (bezoar fragmentation and extraction) [73].

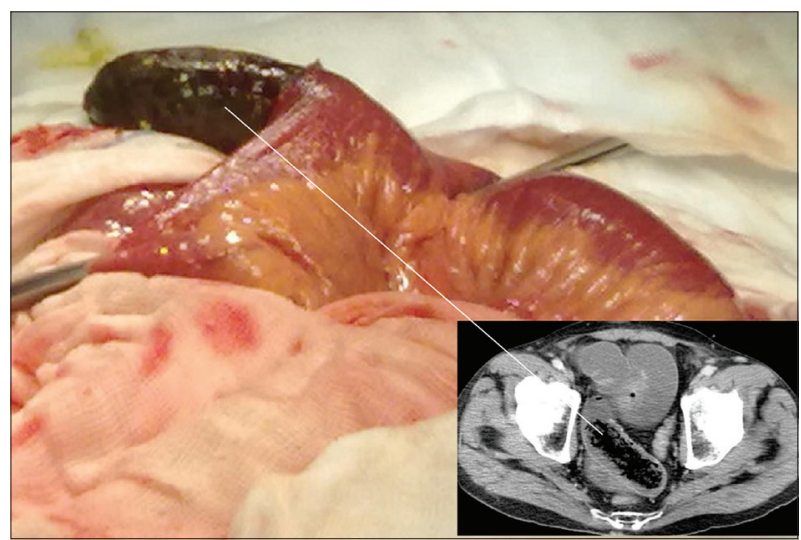

Figure 4 Enterotomy performed via laparotomy on a 68 -year-old man to remove an ileal phytobezoar $(15 \times 5 \mathrm{~cm})$ causing intestinal obstruction (intraoperative and radiological-computed tomography image) 
When bezoars are discovered incidentally and cause no symptomatic pathology, a follow up without any treatment may be an option. Spontaneous disappearance of these masses under no treatment has been described in some patients. The nature and etiology of such bezoars, along with their successful digestion or transportation through the bowel, should be investigated and clarified [31].

\section{Certain features of concern regarding therapeutic options}

Complying with the aforementioned current experimental and clinical data, the therapeutic approach should definitely follow a detailed medical history and monitoring of the patient. If the patient is of advanced age and suffers from severe chronic disorders (cardiac or respiratory insufficiency, renal failure, etc.) chemical dissolution should be excluded. Endoscopic fragmentation may be a reliable option for gastric bezoars, except for persimmon phytobezoars or trichobezoars, which are of very hard consistency. Endoscopists should exert maximum effort to disintegrate the masses into small pieces and extract all of them, taking into consideration that relatively large fragments may migrate to the small intestine causing obstruction or rarely perforation.

Surgery may be the optimal strategy for intestinal bezoars, giant masses, complicated cases with ileus and/or perforation, as well as cases where other techniques have failed. Preoperative accurate radiologic imaging is mandatory. Laparoscopic techniques may precede open surgery, if they are available and feasible.

\section{Our experience}

We studied 9 patients with phytobezoars diagnosed within the last 5 years; 4 were women and 5 men. Their mean age was 67.3 years (Table 1$)$. The majority of the patients (5/9) had a history of some type of gastric surgery. The most common symptom was abdominal pain, while CT was the main diagnostic modality. Most of the phytobezoars were discovered in the small intestine, less than $1.5 \mathrm{~m}$ proximal to the ileocecal valve. The male patient (\#2) had a gastric (fundus) grape phytobezoar diagnosed on upper GI endoscopy without severe symptoms. He received $3 \mathrm{~L}$ of CC orally within $24 \mathrm{~h}$ and a repeat endoscopy 2 days later showed no obvious gastric mass (Fig. 5). The female patient (\#3) had a very rare presentation with a double mass [74]. The phytobezoar located in the ileus was removed via an enterotomy; the gastric one was revealed on a second CT postoperatively, when the patient presented a transient jaundice due to the temporary impaction of the mass into the duodenum. Upper GI endoscopy revealed duodenal ulcers and a gastric bezoar, endoscopically fragmented with a snare and removed (Fig. 6). The female patient $(\# 5)$ had a large ileal phytobezoar $(75 \times 8 \mathrm{~cm})$ that caused intestinal obstruction and perforation. The mass was removed surgically and intestinal resection was performed along with primary anastomosis (Fig. 7).
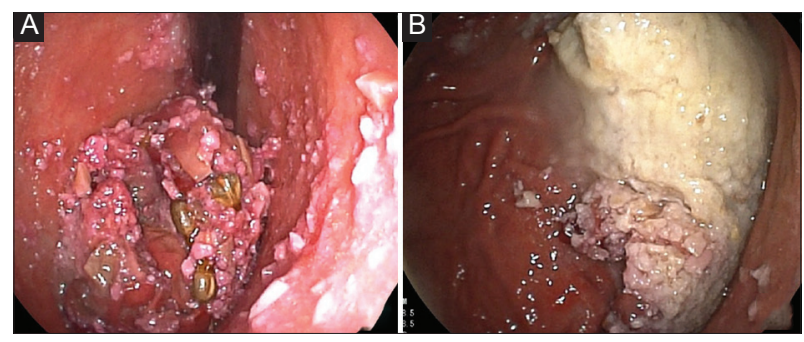

Figure 5 Gastric phytobezoar (grape skins and seeds) discovered in a 52-year-old man and treated with CocaCola ${ }^{\circ}$ per os (A. retroflexed view, B. forward view)
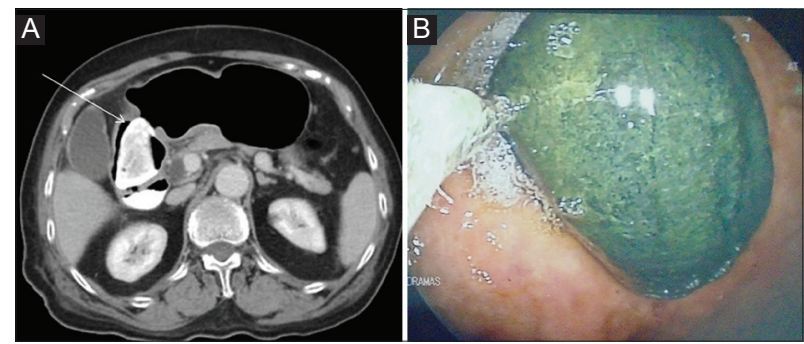

Figure 6 (A) Contrast-enhanced computed tomography showing a duodenal phytobezoar (arrow). (B) Phytobezoar $(5 \times 10 \mathrm{~cm})$ fragmentation in the stomach with an ordinary oval $30 \mathrm{~mm}$ polypectomy snare (endoscopic view)
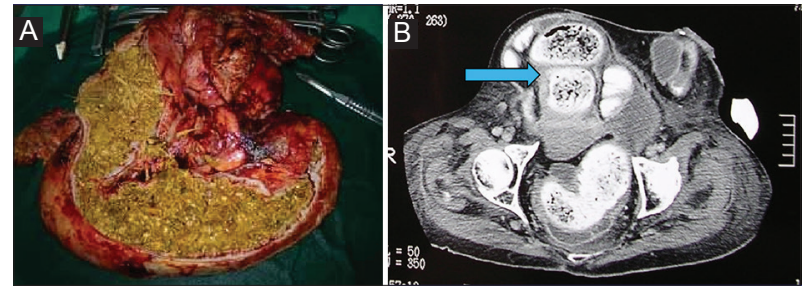

Figure 7 (A) Large ileus phytobezoar $(75 \times 8 \mathrm{~cm})$ that caused obstruction and perforation of the small bowel. (B) Intraoperative and radiological-computed tomography image (arrow)

\section{Concluding remarks}

As human aging becomes a global phenomenon, bezoars become an increasingly recognized entity, responsible for peptic complications such as ulcers, bleeding, obstruction or perforation of the GI tract. Poor mastication, medications, past gastric surgery and dysmotility, which increasingly affect older ages, are the predominant predisposing factors for the majority of bezoar types. Notably, the synergistic effect of multiple factors, usually for a long time, may eventually lead to bezoar development. Modern technology exploited in GI endoscopy and CT imaging considerably facilitates the accurate diagnosis of bezoars and increases their incidence. In addition, advances in technology offer reliable therapeutic solutions, such as endoscopic fragmentation and removal or laparoscopic surgical treatment. Undoubtedly, older approaches, such as chemical bezoar resolution or open surgery, still retain their crucial role. Laparotomy remains the main (occasionally the only) option, especially in complicated cases. Future research should better investigate the chemical synthesis and the etiology of bezoars, 
8 K. A. Paschos and A. Chatzigeorgiadis

Table 1 Our experience (diagnosis and treatment) with bezoars

\begin{tabular}{|c|c|c|c|c|c|c|c|}
\hline No & Sex & Age & Medical history & Symptoms-signs & $\begin{array}{l}\text { Diagnostic } \\
\text { technique }\end{array}$ & Location & Therapeutic technique \\
\hline 1 & $\mathrm{~F}$ & 75 & gs & ap, vomiting & $\mathrm{CT}$ & Stomach & Laparotomy (gastrotomy) \\
\hline 2 & M & 52 & $\mathrm{dm}$ & $\begin{array}{l}\text { ap, difficulty of } \\
\text { swallowing }\end{array}$ & $\begin{array}{l}\text { gastroduode- } \\
\text { noscopy }\end{array}$ & Stomach & Coca-Cola \\
\hline 3 & $\mathrm{~F}$ & 83 & $\begin{array}{l}\text { hypertension, } \\
\text { hyperlipidemia }\end{array}$ & $\begin{array}{l}\text { ap, distention, } \\
\text { jaundice }\end{array}$ & $\begin{array}{l}\text { CT (double } \\
\text { phytobezoar) }\end{array}$ & Stomach+ileus & $\begin{array}{l}\text { Gastroscopy } \\
\text { (fragmentation)+ } \\
\text { Laparotomy (enterotomy) }\end{array}$ \\
\hline 4 & M & 68 & gs & ap, vomiting & $\mathrm{CT}$ & ileus & Laparotomy (enterotomy) \\
\hline 5 & $\mathrm{~F}$ & 72 & $\begin{array}{l}\text { abdomino-perineal } \\
\text { resection }\end{array}$ & $\begin{array}{l}\text { ap, constipation- } \\
\text { no flatus }\end{array}$ & $\begin{array}{l}\text { CT (ileal } \\
\text { perforation) }\end{array}$ & ileus & $\begin{array}{l}\text { Laparotomy (intestinal } \\
\text { resection) }\end{array}$ \\
\hline 6 & M & 62 & gs, coronary by-pass & ap, distention & CT & ileus & Laparotomy (enterotomy) \\
\hline 7 & M & 51 & gs, appendectomy & ap, vomiting & $\mathrm{CT}$ & ileus & Laparotomy (enterotomy) \\
\hline 8 & $\mathrm{~F}$ & 76 & gs & ap, vomiting & CT & ileus & Laparotomy (enterotomy) \\
\hline 9 & M & 67 & unremarkable & ap, vomiting & CT & ileus & Laparotomy (enterotomy) \\
\hline
\end{tabular}

F, female; $M$, male; gs: gastric surgery; $d m$, diabetes mellitus; ap, abdominal pain; $C T$, computerized tomography

in order to prevent their formation and subsequently their lifethreatening complications.

\section{References}

1. Eng K, Kay M. Gastrointestinal bezoars: history and current treatment paradigms. Gastroenterol Hepatol (N Y) 2012;8:776-778.

2. Kement M, Ozlem N, Colak E, Kesmer S, Gezen C, Vural S. Synergistic effect of multiple predisposing risk factors on the development of bezoars. World J Gastroenterol 2012;18:960-964.

3. Koulas SG, Zikos N, Charalampous C, Christodoulou K, Sakkas L, Katsamakis N. Management of gastrointestinal bezoars: an analysis of 23 cases. Int Surg 2008;93:95-98.

4. Iwamuro M, Okada $\mathrm{H}$, Matsueda $\mathrm{K}$, et al. Review of the diagnosis and management of gastrointestinal bezoars. World J Gastrointest Endosc 2015;7:336-345.

5. Özsoy Z, Okan. Treatment of phytobezoars: Tailoring management to diverse presentations. Turk J Surg 2018;34:33-37.

6. Andrus CH, Ponsky JL. Bezoars: classification, pathophysiology, and treatment. Am J Gastroenterol 1988;83:476-478.

7. Dikicier E, Altintoprak F, Ozkan OV, Yagmurkaya O, Uzunoglu MY. Intestinal obstruction due to phytobezoars: An update. World $J$ Clin Cases 2015;3:721-726.

8. Maki T, Suzuki N. Experimental formation of persimmon-bezoar. Tohoku J Exp Med 1965;86:168-177.

9. Iwamuro M, Urata H, Furutani M, et al. Ultrastructural analysis of a gastric persimmon phytobezoar. Clin Res Hepatol Gastroenterol 2014;38:e85-e87.

10. Erdemir A, Ağalar F, Çakmakçı M, Ramadan S, Baloğlu H. A rare cause of mechanical intestinal obstruction: Pharmacobezoar. Ulus Cerrahi Derg 2015;31:92-93.

11. Simpson SE. Pharmacobezoars described and demystified. Clin Toxicol (Phila) 2011;49:72-89.

12. England G, Heath KJ, Gilbert JD, Byard RW. Forensic features of pharmacobezoars. J Forensic Sci 2015;60:341-345.

13. Gavala A, Manou D, Psalida V, et al. Methadone gastrobezoar in a psychiatric patient presented in coma. Indian J Crit Care Med 2017;21:796-798.
14. Mehra A, Avasthi A, Gupta V, Grover S. Trichophagia along with trichobezoar in the absence of trichotillomania. J Neurosci Rural Pract 2014;5:S55-S57.

15. Yik YI, How AK. A 'Hairy' problem: Trichotillomania, trichophagia and trichobezoars. Singapore Med J 2016;57:411.

16. Gorter RR, Kneepkens CM, Mattens EC, Aronson DC, Heij HA. Management of trichobezoar: case report and literature review. Pediatr Surg Int 2010;26:457-463.

17. Frey AS, McKee M, King RA, Martin A. Hair apparent: Rapunzel syndrome. Am J Psychiatry 2005;162:242-248.

18. Sharma AK, Hussain A, Walia D, Bansal S. Trichobezoar and Rapunzel syndrome: A review. Oncol Gastroenterol Hepatol Rep 2015;4:28-29.

19. Hamidi H, Muhammadi M, Saberi B, Sarwari MA. A rare clinic entity: Huge trichobezoar. Int J Surg Case Rep 2016;28:127-130.

20. Nettikadan A, Ravi MJ, Shivaprasad M. Recurrent Rapunzel syndrome - A rare tale of a hairy tail. Int J Surg Case Rep 2018;45:83-86.

21. Naik S, Gupta V, Naik S, et al. Rapunzel syndrome reviewed and redefined. Dig Surg 2007;24:157-161.

22. Ullah W, Saleem K, Ahmad E, Anwer F. Rapunzel syndrome: a rare cause of hypoproteinaemia and review of literature. BMJ Case Rep 2016;2016.

23. Fallon SC, Slater BJ, Larimer EL, Brandt ML, Lopez ME. The surgical management of Rapunzel syndrome: a case series and literature review. J Pediatr Surg 2013;48:830-834.

24. Castro L, Berenguer A, Pilar C, Gonçalves R, Nunes JL. Recurrent gastric lactobezoar in an infant. Oxf Med Case Reports 2014;2014:80-82.

25. Bos ME, Wijnen RM, de Blaauw I. Gastric pneumatosis and rupture caused by lactobezoar. Pediatr Int 2013;55:757-760.

26. Heinz-Erian P, Gassner I, Klein-Franke A, et al. Gastric lactobezoar - a rare disorder? Orphanet J Rare Dis 2012;7:3.

27. Camacho Dorado C, Sanchez Gallego A, Miota de Llama JI, Gonzalez Masia JA. Metallic bezoar after suicide attempt. Cir Esp 2018;96:515.

28. Chahine E, El Khoury L, Baghdady R, Chouillard E. Recurrent gastric metal bezoar: a rare cause of gastric outlet obstruction. $B M J$ Case Rep 2017;2017.

29. Dokoupil M, Marecová K, Handlos P, Březina P. Death of a female prostitute due to intestinal obstruction by an unknown substance. J Forensic Sci 2019;64:289-291. 
30. Takemura K, Takazawa R, Kohno Y, Yoshida S, Kato H, Tsujii T. Vesical fungus balls (fungal bezoars) by Candida albicans mimicking urothelial carcinoma in a patient with diabetic neurogenic bladder. Urol Case Rep 2018;18:50-51.

31. Kadian RS, Rose JF, Mann NS. Gastric bezoars-spontaneous resolution. Am J Gastroenterol 1978;70:79-82.

32. Ahn YH, Maturu P, Steinheber FU, Goldman JM. Association of diabetes mellitus with gastric bezoar formation. Arch Intern Med 1987; 147:527-528.

33. Mihai C, Mihai B, Drug V, Cijevschi Prelipcean C. Gastric bezoars-diagnostic and therapeutic challenges. J Gastrointestin Liver Dis 2013;22:111.

34. Dervisoglou A, Condilis N, Liveranou S, Pinis S. A causal factors and treatment of obstructive ileus in 369 patients. Ann Ital Chir 2005;76:477-480.

35. Kirshtein B, Roy-Shapira A, Lantsberg L, Avinoach E, Mizrahi S. Laparoscopic management of acute small bowel obstruction. Surg Endosc 2005; 19:464-467.

36. Yakan S, Sirinocak A, Telciler KE, Tekeli MT, Deneçli AG. A rare cause of acute abdomen: small bowel obstruction due to phytobezoar. Ulus Travma Acil Cerrahi Derg 2010;16:459-463.

37. Akrami M, Sasani MR. Dietary habits affect quality of life: bowel obstruction caused by phytobezoar. Iran J Public Health 2016;45:1080-1082.

38. Park SE, Ahn JY, Jung HY, et al. Clinical outcomes associated with treatment modalities for gastrointestinal bezoars. Gut Liver 2014;8:400-407.

39. Granot E, Fich A, Ayalon A, et al. An epidemic of persimmon bezoars in Israel. Isr J Med Sci 1984;20:167-169.

40. Bowden TA Jr, Hooks VH $3^{\text {rd }}$, Mansberger AR Jr. The stomach after surgery. An endoscopic perspective. Ann Surg 1983;197:637-644.

41. Gasparella M, Marzaro M, Ferro M, et al. Meckel's diverticulum and bowel obstruction due to phytobezoar: a case report. Pediatr Med Chir 2016;38:117.

42. Tayeb M, Khan FM, Rauf F, Khan MM. Phytobezoar in a jejunal diverticulum as a cause of small bowel obstruction: a case report. J Med Case Rep 2011;5:482.

43. Erzurumlu K, Malazgirt Z, Bektas A, et al. Gastrointestinal bezoars: a retrospective analysis of 34 cases. World J Gastroenterol 2005; 11:1813-1817.

44. Çebi Olgun D, Kayadibi Y, Şimşek O, Karaduman Z. The journey of gastric phytobezoar followed by tomography. Ulus Travma Acil Cerrahi Derg 2014;20:389-391.

45. Iwamuro M, Tanaka S, Shiode J, et al. Clinical characteristics and treatment outcomes of nineteen Japanese patients with gastrointestinal bezoars. Intern Med 2014;53:1099-1105.

46. Altintoprak F, Dikicier E, Deveci U, et al. Intestinal obstruction due to bezoars: a retrospective clinical study. Eur J Trauma Emerg Surg 2012;38:569-575.

47. Pujar K A, Pai A S, Hiremath V B. Phytobezoar: a rare cause of small bowel obstruction. J Clin Diagn Res 2013;7:2298-2299.

48. Yamagata Y, Saito K, Hirano K, et al. Obstruction in the third portion of the duodenum due to a diospyrobezoar: a case report. BMC Surg 2017;17:117.

49. Pérez-Rodríguez P, Ramírez-Martín R, Rodríguez-Sánchez I, Mauleón-Ladrero MDC. Esophageal bezoar in a patient with a diffuse esophageal spasm. Rev Esp Geriatr Gerontol 2018 Oct 31 [Epub ahead of print].

50. Barrows A, Vachon T, Campin RC, Ignacio RCJr. Trichobezoars detected and treated based on plain radiography. Mil Med 2015;180:e1136-e1138.

51. Altintoprak F, Degirmenci B, Dikicier E, et al. CT findings of patients with small bowel obstruction due to bezoar: a descriptive study. Sci World J 2013;2013:298392.

52. Chen YC, Liu $\mathrm{CH}, \mathrm{Hsu} \mathrm{HH}$, et al. Imaging differentiation of phytobezoar and small-bowel faeces: CT characteristics with quantitative analysis in patients with small- bowel obstruction. Eur Radiol 2015;25:922-931.

53. Lee KH, Han HY, Kim HJ, Kim HK, Lee MS. Ultrasonographic differentiation of bezoar from feces in small bowel obstruction. Ultrasonography 2015;34:211-216.

54. Wang PY, Wang X, Zhang L, et al. Bezoar-induced small bowel obstruction: Clinical characteristics and diagnostic value of multi-slice spiral computed tomography. World J Gastroenterol 2015;21:9774-9784.

55. Chun J, Pochapin M. Gastric diospyrobezoar dissolution with ingestion of diet soda and cellulase enzyme supplement. ACG Case Rep J 2017;4:e90.

56. Cerezo Ruiz A, Domínguez Jiménez JL, Uceda-Vaño A. Cellulase, Coca-Cola(R), pancreatin and ursodeoxycholic acid in the dissolution of gastric bezoars: why not all together? Rev Esp Enferm Dig 2018;110:472-473.

57. Kramer SJ, Pochapin MB. Gastric phytobezoar dissolution with ingestion of diet coke and cellulase. Gastroenterol Hepatol (N Y) 2012;8:770-772.

58. Ladas SD, Kamberoglou D, Karamanolis G, Vlachogiannakos J, Zouboulis-Vafiadis I. Systematic review: Coca-Cola can effectively dissolve gastric phytobezoars as a first-line treatment. Aliment Pharmacol Ther 2013;37:169-173.

59. Qin B, Wan XL, Guo XY, Dong L. Successful endoscopic treatment of an intestinal diospyrobezoar migrated from the stomach. $B M J$ Case Rep 2014;2014.

60. Lu L, Zhang XF. Gastric outlet obstruction-an unexpected complication during Coca-Cola therapy for a gastric bezoar: a case report and literature review. Intern Med 2016;55:1085-1089.

61. Gold MH Jr, Patteson TE $3^{\text {rd }}$, Green GI. Cellulase bezoar injection: a new endoscopic technique. Gastrointest Endosc 1976;22:200-202.

62. Pollard HB, Block GE. Rapid dissolution of phytobezoar by cellulase enzyme. Am J Surg 1968;116:933-936.

63. Ugenti I, Travaglio E, Lagouvardou E, Caputi Iambrenghi O, Martines G. Successful endoscopic treatment of gastric phytobezoar: a case report. Int J Surg Case Rep 2017;37:45-47.

64. Mao Y, Qiu H, Liu Q, et al. Endoscopic lithotripsy for gastric bezoars by Nd: YAG laser-ignited mini-explosive technique. Lasers Med Sci 2014;29:1237-1240.

65. Senturk O, Hulagu S, Celebi A, et al. A new technique for endoscopic treatment of gastric phytobezoars: fragmentation using guidewire. Acta Gastroenterol Belg 2014;77:389-392.

66. Maini A, John J. Trichobezoar requiring surgical intervention. JAAPA 2018;31:32-34.

67. Aysan E, Demir M, Kinaci E, Basak F. Complications of intestinal milking: experimental model. ANZ J Surg 2005;75:322-325.

68. Horesh N, Rosin D, Dreznik Y, et al. A single tertiary center 10-year experience in the surgical management of gastrointestinal bezoars. J Laparoendosc Adv Surg Tech A 2018;28:967-971.

69. Castle SL, Zmora O, Papillon S, Levin D, Stein JE. Management of complicated gastric bezoars in children and adolescents. Isr Med Assoc J 2015; 17:541-544.

70. Javed A, Agarwal AK. A modified minimally invasive technique for the surgical management of large trichobezoars. J Minim Access Surg 2014;9:42-44.

71. Sharma D, Srivastava M, Babu R, Anand R, Rohtagi A, Thomas S. Laparoscopic treatment of gastric bezoar. JSLS 2010;14:263-267.

72. Ulukent SC, Ozgun YM, Şahbaz NA. A modified technique for the laparoscopic management of large gastric bezoars. Saudi Med J 2016;37:1022-1024.

73. Kurosu T, Tanabe S, Hasegawa R, et al. A giant trichobezoar extracted by laparoscopic and endoscopic cooperative surgery (LECS). Endosc Int Open 2018;6:E1413-E1416.

74. Paschos KA, Chatzigeorgiadis A. Surgical and endoscopic treatment of a double phytobezoar causing ileus and jaundice: a case report. Iran J Med Sci 2019;44:70-73. 